\title{
Intelligent accident identification and location display system using ARM
}

\author{
${ }^{1}$ G. Vara Prasad Reddy, ${ }^{2}$ D. Rupa kumar, ${ }^{3}$ K. Srinivasa Reddy, \\ 1,2,3 Department of the Electronics and Communication Engineering, NITS, Hyderabad, AP, India.
}

\begin{abstract}
Now a day's everyone is busy with their regular activities such as their jobs, parties, vacations, text messages, facebook, blackberry bbms, new relationships, nobody is ready to look what's happening around them. In India, an accident happens every 60 seconds and every 3.7 minutes, to be precise, a road mishap snuffs out a life, some can be saved if the victim has been given medical care as soon as possible. This is an intention to develop intelligent accident identification and location display system. This system has been developed and implemented using the smart sensors and LPC2148 controller based mobile technology. This system decreases the speed of vehicle when it detects any vehicle or collision particle to avoid accident, if the accident occurred then this system immediately transmit the location of the accident and person's heart beat status to the emergency care centre phone number through Short Message Service (SMS). In addition to this this system sends a SMS if it detects fire accident or vehicle is flipped. When the accident occurs and no one is damaged then the person involved in accident has to press the safety switch which has been made to indicate that the accident is small and no communication will be established i.e. no SMS will send to emergency care centre.
\end{abstract}

Index Terms: Accident avoidance, Accident detection, SMS

\section{Introduction}

India ranks worst when it comes to road accidents. A supportive legal framework is the need of the hour for good Samaritans who provide emergency medical care to road accident victims in order to shield them from unnecessary legal complications. Every year nearly 150,000 people die in road accidents in India, which is the highest number in the world. The first hour of such an emergency, called the 'golden hour' is widely regarded as the most precious time for saving lives. The 201 Law of Commission had stated, "Doctors point out that at least fifty per cent of the fatalities can be averted if victims are admitted to a hospital within the first one hour". According to organizations working in the sphere of trauma care, "If the victim can be displaced to a hospital in time frame, his or her chances of survival increase significantly."

Unfortunately, however, such prompt care is generally not available in India. According to a study by the Indian Journal of Surgery in 2006, 80 percent of road accident victims in India do not receive any emergency medical care within this 'golden hour'.

According to a survey conducted for Save Life Foundation (SLF), an organization that works in the sector, among 1,027 road-users in Hyderabad, Kanpur, Delhi, Ludhiana, Mumbai, Kolkata and Indore, 74 per cent of the bystanders are unlikely to assist a victim of serious injury. When asked the reasons behind it, 88 per cent of the respondents said that they were unwilling to help because of fear of legal complications, including continual police questioning and court appearances, 77 per cent said that hospitals unnecessarily detain helpful persons and refuse treatment if payment is not made promptly [2].

The primary step to correct this deficiency is to develop a system which detects accident automatically and inform to emergency care centre to take proper action within a time frame. According to recent World Health Organization (WHO) India has the highest number of road deaths in 2012 in the world.

Table 1

\begin{tabular}{|l|l|}
\hline Country & Number of road deaths \\
\hline India & 105,725 \\
\hline China & 96,611 \\
\hline US & 42,642 \\
\hline Russia & 35,972 \\
\hline UK & 3,298 \\
\hline
\end{tabular}

Worldwide, 1.3 million lives were lost. Road accidents also create enormous losses to the exchequer. India loses $\$ 20$ billion due to road accidents annually which is enough to feed $50 \%$ of the nation's malnourished children.

Among the states, Maharashtra topped the list with the highest number of road accidents at 68,438 , Tamil Nadu $(65,873)$, Madhya Pradesh $(49,406)$, Karnataka $(44,731)$ and Andhra Pradesh $(44,165)$. Mumbai topped the list of cities with 25,471 road accidents, Delhi is in second with 7281 road accidents followed by 
Bangalore (6031), Indore (4995) and Bhopal (3459).In another disturbing trend, of the total number of road accidents, 53.5 per cent were reported from rural areas, reflecting a rising tide of motorization in rural India[1]. In recent years accidents due to dense fog also increasing.

A vehicle fire is an undesired conflagration (uncontrolled burning) involving a motor vehicle. Also termed auto fire or car fire, it is one of the most common causes of fire related property damage. A motor vehicle contains many types of flammable materials, including flammable liquids like oil and gasoline as well as solid combustibles.

Seat belts save lives. While seat belt use has been increasing and averages $88 \%$ nationally, there are still groups less likely to wear seat belts: commercial drivers, teens, males in rural areas, people driving at night, pick-up truck drivers and people who have been drinking.

The above information causes to develop this system.

The main objectives of this system are:

1. To avoid the accidents by decreasing the speed of vehicle when it detects any vehicle or object in front to vehicle.

2. To detect the accident and inform the accident and persons heart beat status to emergency care centre.

3. To inform emergency care centre when it detects vehicle flipping or fire.

The proposed system is to avoid accidents, automatic accident detection and intimation to emergency care centre to provide emergency medical care within 'golden hour'.

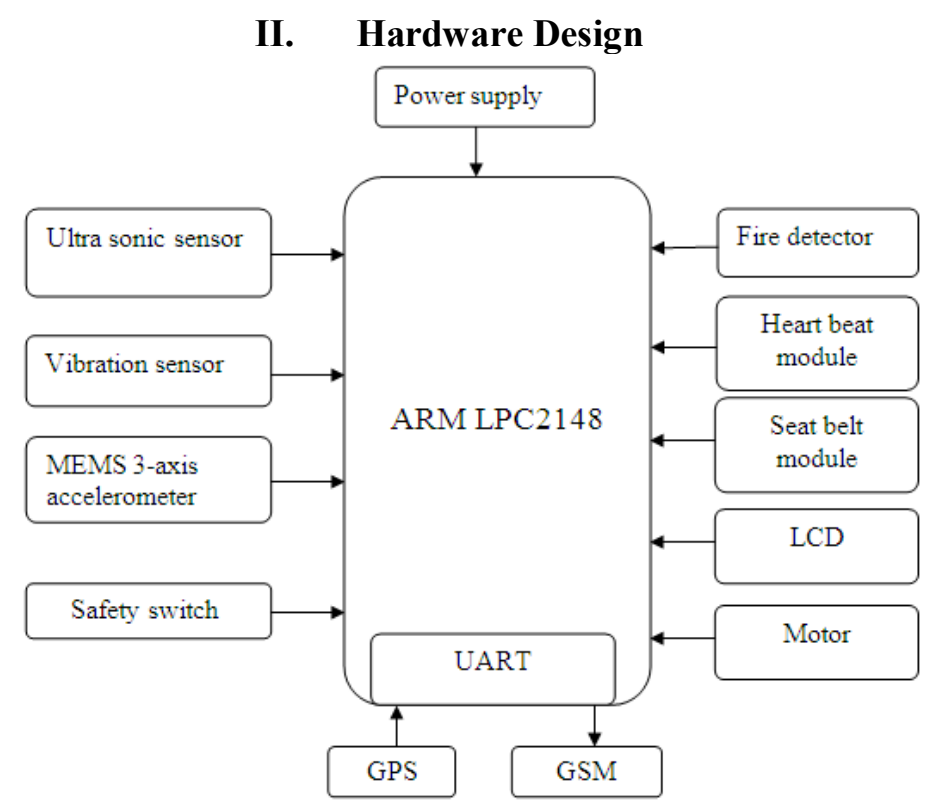

Fig: Block diagram of proposed system

\section{Accident avoidance:}

Ultrasonic sensors generate high frequency sound waves at regular time intervals. These propagate in the air at the velocity of sound. If they strike an object, then they are reflected back as echo signals to the sensor. This reflected echo signals further processed to decrease the vehicle speed. Ultrasonic's are a great solution for clear object detection.

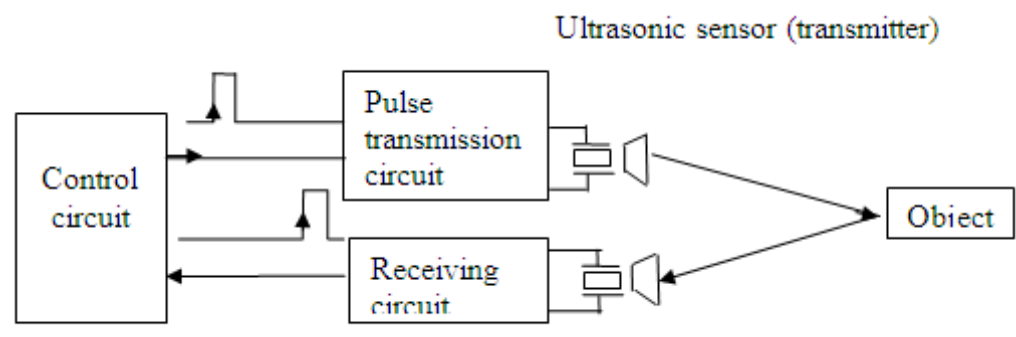

Ultrasonic sensor (receiver)

Fig: Block diagram of ultrasonic sensor 


\section{Accident detection:}

(a). Vibration sensor:

For accident detection we are using a vibration switch which internally buffers a piezoelectric transducer. When the vehicle is rammed with any another or to any objects then the switch comes into contact with piezo material. Then the piezo material generates measurable output voltage that is proportional to applied force or stress. This output voltage is further processed to activate the GPS and GSM to send SMS to emergency care centres.

\section{(b). MEMS 3-axis accelerometer:}

MEMS 3-axis accelerometer consists of a mass at the centre of the sensor's chip, which is suspended by 4 beams doped with piezo resistive material. When the sensor is subjected to acceleration in any direction, the movement of the mass causes the 4 beam to deform and so change the resistance in the piezo material. This change in resistance will cause the change in electron flow, this current is converted into voltage using $\mathrm{C}$ to $\mathrm{V}$ converter and then amplified using gain factor.

\section{(c). Fire detector:}

IR (infrared) fire detectors observe the heat radiation emitted by fire and open flames, with a response time of 5 to 8 seconds. Working within the infrared spectral band, these flame detectors have a sensitivity range between approximately 4.3 to 4.4 micrometers. This range covers the resonance frequency of $\mathrm{CO} 2$, which is generated in large amounts by the burning of hydrocarbon materials, such as wood and fossil fuels. Hot CO2 gases from fires produce a radiation emission, as well as a spectral pattern in the infrared range, which are easily detectable by Infrared flame detectors.

\section{Heart rate measuring module:}

Heart rate measuring module unit consists of an infrared light-emitting-diode (IR LED) and a detector, placed side by side, and the finger is placed over the sensor assembly. The IR LED transmits an infrared light into the finger, a part of which is reflected back from the blood inside the finger changes. The detector senses the portion of the light that is reflected back. The intensity of reflected light depends upon the blood volume inside the finger. So, every time the heart beats the amount of reflected infrared light changes, which can be detected by the detector. With a high gain amplifier, this little change in the amplitude of the reflected light can be converted into a pulse further for the LPC2148 controller to count the rate of fluctuation, which is actually the heart beat rate.

\section{GPS:}

The Global Positioning System (GPS) is a space-based navigation system made up of a network of 24 satellites, 21 of which are active while 3 are spares and are located at an altitude of 10600 miles above the surface of the earth, which are continuously rotating around the earth. GPS was originally intended for military applications, but in the 1980s, the government made the system available for civilian use. GPS receiver provides three-dimensional location (latitude, longitude, and altitude) plus the time with Irrespective of time, location, and weather. There are no subscription fees or setup charges to use GPS.GPS segments are categorized into three distinct segments that include space segment, control segment, and user segment. Farmers, surveyors, geologists and countless others perform their work more efficiently, safely, economically, and accurately using the free and open GPS signals.GPS is also an essential synchronization resource of cellular networks.

\section{GSM:}

GSM, which stands for Global system for mobile communications (GSM) is a second-generation digital technology, which was originally developed by Europe but now has in excess of 75 per cent of the world market. For efficient transmission of digital voice and data service, GSM is a very advanced technology, mobile phones connect to it by searching for cells in the immediate vicinity. There are five different cells in a GSM network - micro, macro, femto, umbrella and pico cells. Every cell varies with the coverage range, according to the implementation environment. GSM networks works on different frequency ranges, 2G GSM networks works in the $900 \mathrm{MHz}$ spectrum and later introduced on $1800 \mathrm{MHz}$ band. $900 \mathrm{MHz}$ GSM works with the combination of both TDMA and FDMA at the data rate of $9.6 \mathrm{kbps}$.

\section{Operation And Results}

The Intelligent accident identification and location display system working is same as flow chart shown below. When the driver starts engine it checks whether the driver has wear the seat belt or not. If the seat belt is not wear then the engine could not started and it will show a message WEAR SEAT BELT on display. After wearing the seat belt driver has to start the engine then the engine will be ignited and it will show a message 
HAPPY JOURNEY. While moving if it detects a vehicle or any other objects it will decreases the vehicle speed, even though the accident occurred then vibration sensor will activate the GPS to locate accident area. If there is no affect to anyone then the person involved in accident has to press the safety switch. In this case no SMS will send to emergency care centre. If no one is pressed the safety switch within 40s then GSM will send the location and persons heart beat status to the emergency care centre and optional mobile number stating that ACCIDENT OCCURRED. In addition to that it will send a message to emergency care centre when the vehicle is flipped or detects the fire.

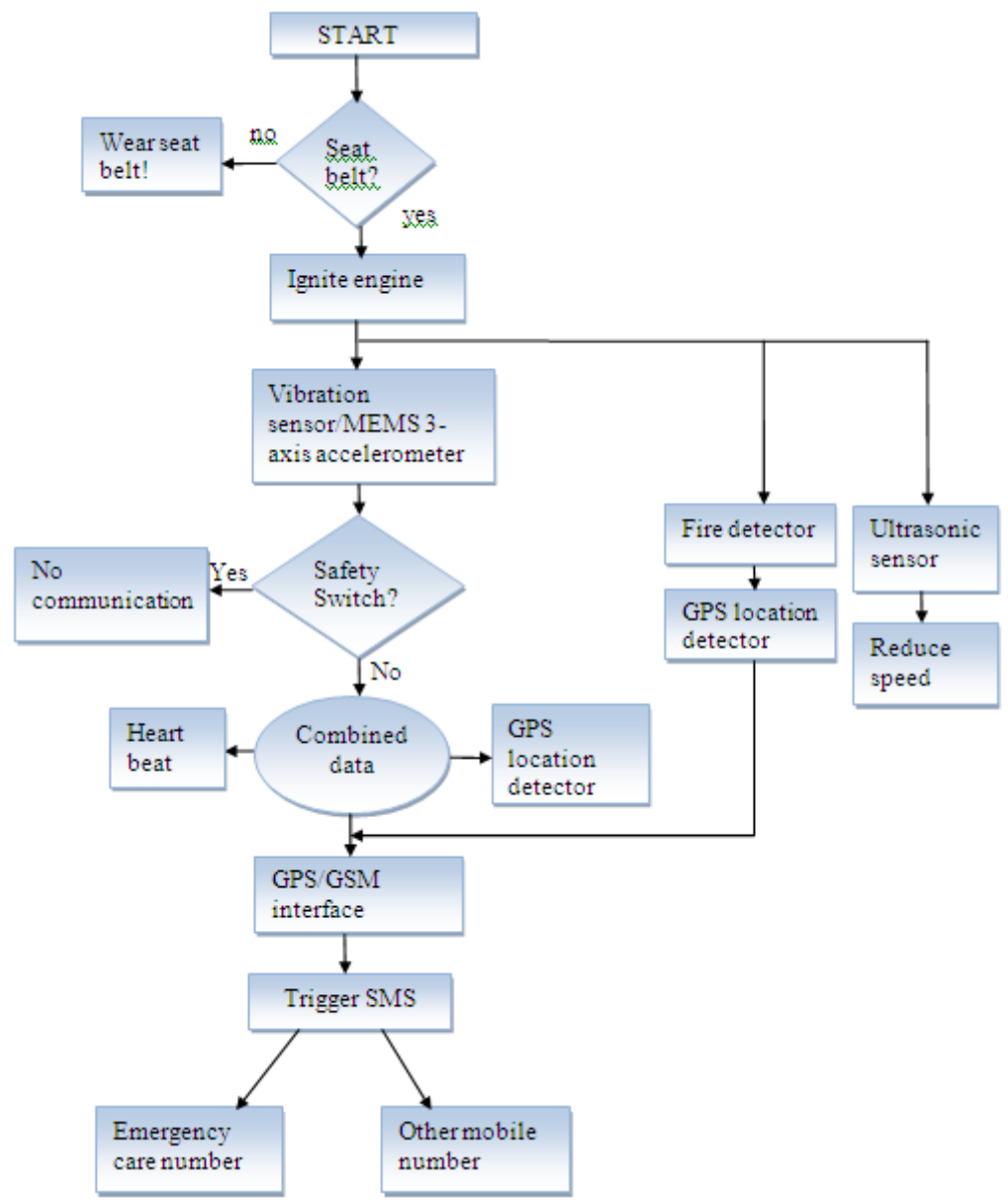

Fig: Flow chart of proposed system
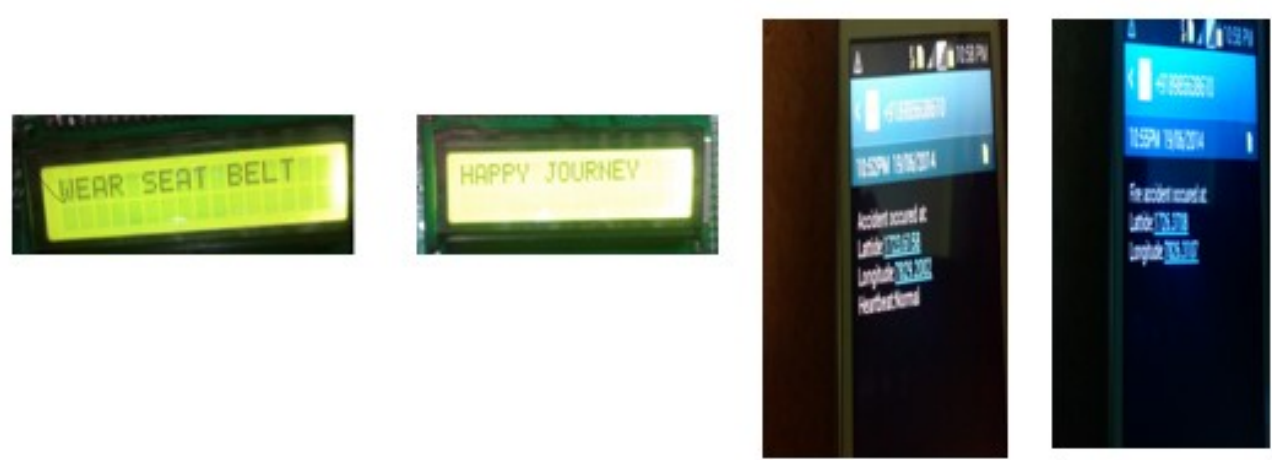

Fig: Photographs of LCD display indications and accident occurred, location and heart beat status messages send to mobile phones 


\section{Conclusion And Future Enhancement}

In this paper we defined a complete solution for detecting the all type of accidents that occurred on roads. In this system initially we try to avoid accidents which occurred due to adverse weather conditions (i.e. dense fog) by decreasing the speed, even though the accident occurred the vibration or MEMS sensor will activate the GPS to find the location and further SMS will send to emergency care centre. This will optimize accidents as well as human death ratio by accidents due to providing proper care with in time frame. As an additional we also added fire sensor to detect fire accidents. Thus this system will provide a vital information about the accidents, however such prompt system is not available in the country.

For future enhancement we can enhance this as per user need. This system would be designed in such a way that if the fire is detected by fire sensor this will automatically activate the releasing of gases that stop fire. Moreover, this system can be designed to handle the steering when the ultrasonic sensor detects any vehicle or collision particle.

\section{Acknowledgment}

The authors would like to thank Mr.K.Srinivasa Reddy,Associate Professor, for providing necessary facilities to carry out this work. A special gratitude to my parents for their constant encouragement without which this assignment would not be possible.

\section{References}

[1]. Rajiv Theodre, "Road to hell-every 3.7 minutes, death swoops in " Available online at:TheAmericanBazar http://www.americanbazaaronline.com/2013/08/21/road-to-hell-every-3-7- minutes-death-swoops-in/, August 21, 2013.

[2]. Bharat Dogra, "Save the golden hour" Avilable online at: The Hindu http://www.thehindu.com/features/metroplus/society/savethe-golden-hour/article5268987.ece, october 25, 2013.

[3]. National Safety Council, Available online at: http://www.nsc.org/safety_road/DriverSafety/Pages/SeatBelts.aspx

[4]. 45 dead in bus fire near mahabubnagar" available online at: Sakshipost http://www.sakshipost.com/index.php/news/state/29022-42dead-in-bus-fire-near-hyderabad.html.

[5]. Available online at: http://en.wikipedia.org/wiki/Vehicle_fire.

[6]. The National, "Fog-related road accidents accross the UAE " Available online at: http://www.thenational.ae/uae/transport/fogrelated-road-accidents-across-the-uae.

[7]. Prabakar,Porkumaran,Samson Isaac,Guna Sundari, "An Enhanced accident detection and victim status indicating system" 2012 IEEE

[8]. ARM lpc2148 manual Available online at:https://www.google.co.in/\#q=arm+lpc2148

[9]. Accelerometer Factsheet, available online at:https://www.google.co.in/\#q=mems +3 -axis + accelerometer

[10]. Dogan Ibrahim, Kadri Buruncuk, "Heart Rate Measurement from the Finger Using a Low-Cost Microcontroller" Available online at: www.emo.org.tr/ekler/a568a2aa8c19a31_ek.pdf 